\title{
Analysis of Individual Aspects Influencing Non-purchasing in an Online Environment and Consumer Willingness to Purchase Custom-Made Apparel
}

\author{
Milica ŽURAJ1, Petra ŠPARL ${ }^{2}$, Anja ŽNIDARŠıč² \\ ${ }^{1}$ Independent researcher, Ljubljana, Slovenia \\ milica@zuraj.com \\ ${ }^{2}$ University of Maribor, Faculty of Organizational Sciences, Kranj, Slovenia \\ anja.znidarsic@fov.uni-mb.si
}

\begin{abstract}
Purpose: The main purpose of the study was to assess the opinion of online consumers about the possibility of making custom apparel using 3D body scanning technology in an online environment and to investigate the shopping experience of consumers who purchase in the online apparel market. In order to be able to propose solutions to improve the online shopping experience, we also investigated aspects influencing non-purchasing in an online environment. Methods: An online questionnaire on shopping experience, influences on the purchase, and the process of online apparel shopping using advanced technology was prepared and distributed via several online channels to the consumers who purchase apparel online. The questionnaire was completed by 76 respondents from different European countries, the United States and Australia. In order to analyze individual aspects influencing non-purchasing in an online environment, an exploratory factor analysis was performed.

Results: The factor analysis revealed that the two broad dimensions of reasons why consumers have never bought any ready-to-wear apparel online despite browsing are a misperception of product integrity and time-consuming searching. The results show that the proposed solutions to improve the online apparel experience, such as making custom apparel using advanced technologies, have a positive impact on the decision of the consumers to purchase on the online apparel market. It turned out that a high proportion of potential consumers are willing to share their body dimensions through 3D body scanning technology in order to improve the fit of the apparel.

Conclusion: According to the results, we expect that the advanced 3D body scanning technology would provide substantial progress regarding fit, visualization, and manufacturing of custom-made apparel when purchasing in online stores.
\end{abstract}

Keywords: online shopping apparel; custom made apparel; consumers' shopping experience

\section{Introduction}

The main idea and motive for this research paper derives from the fact that the consumer wants to purchase high-quality apparel, which satisfies their fitting preferences, in an easy and cost-effective manner. This is not a problem when it comes to small brick-and-mortar shops where the consumer can touch the fabric, look at the color, try on the apparel, etc. The challenge arises in online apparel stores, where the consumer is able to evaluate the apparel qualities only virtually. Online apparel stores provide consumers with various benefits, such as saving time and money, 24-hour availability, better service in general, a fast (and easy) process of shopping and a greater choice of products compared with brick-and-mortar shops (Monsuwe, Dellaert, \& Ruyter, 2004; Loker, Ashdown, Cowie, 
\& Schoenfelder, 2004; Orzan, Iconaru, Popescu, Orzan, $\&$ Macovei, 2013). However, it is well known that a high proportion of the returned apparel purchased in an online store is due to the inability to find the right size and/or due to the dissatisfaction with the fit of ready-to-wear apparel. Also, according to Olaru, Filipescu, Niculescu, and Filipescu (2013) "unsold products do not reflect that they are obsolete or do not have the best quality in terms of accuracy of manufacturing technology, appropriate use of raw and auxiliary materials, but they were not purchased because they do not correspond to the dimensional morphological requirements of the users". The cause of this problem stems from the standardization of the apparel sizing system, either due to the obsolescence of the existing standards or variations in body shapes and sizes that the existing standards do not account for, or due to the size disparity between the apparel suppliers. Most manufacturers of ready-to-wear apparel set standard sizes depending on their target market (Ashdown \& Dunne, 2006; Faust, Carrier, \& Baptiste, 2006; Kim \& LaBat, 2013). However, many groups (slim, plus-size, very tall, elderly women, black women and others) do not belong to the target group of the clothing industry and thus they cannot find apparel that fits their body size and desired style (Ashdown \& Dunne, 2006; Romeo \& Lee, 2015).

Gültepe and Güdükbay (2014) emphasized that trying the apparel on is one of the most time-consuming stages of apparel shopping, and the problem of fitting ready-to-wear clothes is especially present in online shopping. When purchasing apparel online, consumers are unable to touch and feel the apparel (Wu, Hwang, Sharkhuu, Tsogt Ochir, 2017). To facilitate the evaluation of fit of ready-to-wear apparel to the individual body shape, some online retailers already enable consumers to use virtual fitting rooms for trying on the apparel on their website through virtual models tailored to the physical dimensions of their body. However, the existing virtual models cannot fully capture the properties of the human body (Pilar, Stjepanovič, \& Jevšnik, 2013). According to Kozar et. al. (2014) "virtual body models are limited to a standing posture with standard body shape characteristics". Also, getting the physical dimensions of the consumer (height, bust, waist, hips and arms) is based on the self-measurement (using a measuring tape) which has certain drawbacks (see Ashdown \& Dunne, 2006; Park, Nam, Choi, Lee, \& Lee, 2009).

Despite the efforts of online retailers to provide a better virtual experience using the help of interactive technology, it is first necessary to solve the problem of the current system of ready-made apparel sizes and to enable a reliable acquisition of the physical dimensions of consumers. Ives and Gabriele (2003) emphasized that it is important to improve the consumers' satisfaction and comfort, where a good alternative to stock sizing is a custom-made clothing service (as cited in Kim et al., 2017).

The solution that we propose could be purchasing cus- tom-made apparel online using innovative technologies. Integrated anthropometry information technology (3D body scanner, WEB camera) and CAD/CAM software, which includes 3D virtual apparel simulation software, provide an opportunity for purchasing custom-made apparel over the Internet. With the anthropometry information technology, $" 3 \mathrm{D}$ digitized anthropometric data can easily be collected in a few seconds and accessed immediately from anywhere in the world through the Internet" (Niculescu, Mielicka, Salistean, Napieralska, Popescu, \& Mocenco, 2016). This would guarantee that apparel would satisfy the requirements of the consumers. The consumers' preferences regarding apparel fit may be defined as the relationship between the body, garment dimensions, and the expectations the wearer has in regard to the fit (Chattaraman, Simmons, \& Ulrich, 2013). Therefore, shopping for custom-made apparel via the Internet can solve the issues consumers have when purchasing ready-to-wear apparel.

In our study we investigated the experiences of consumers when shopping for apparel online and their shopping habits. Therefore, the purpose of our study was to determine the shopping experiences of consumers who purchase in the online apparel market and to analyze the willingness of potential consumers to purchase custom-made apparel in the online apparel market. In addition, we investigated if the offered solutions that incorporate advanced technologies on the Internet would improve their online shopping experience of the apparel and whether they would be willing to entrust volunteering their body dimensions to online retailers.

\section{Literature Review}

Online consumers are searching and evaluating information regarding the effectiveness of apparel through the virtual product experience (Yu, Lee, \& Damhorst, 2012). Therefore, online shops on their websites try to provide the consumer with the most realistic experience, similar to shopping in a brick-and-mortar store. This is achieved through the integration of advanced image interactive technology (Yu et al., 2012), which enables the creation and manipulation of the products or the environment to simulate the actual experience with the product and the environment (Yang \& Young, 2009), for example: expansion or zoom, 3D rotation and personal 3D models in a virtual fitting room for trying on apparel. Per authors Loker, Ashdown, and Carnrite (2008); Kim and LaBat (2013); Yang and Young (2009); Boonbrahma, Kaewrata, and Boonbrahma (2015) virtual fitting technology in the online store solves problems such as the fit of ready-to-wear apparel, choosing the appropriate size and style, and overconsumption of time on the purchase.

Most online stores on their websites provide information about standard sizes and the measurement procedure which helps the consumers to choose the appropriate size 
more easily. Some online stores on their websites also offer virtual fitting rooms, where the physical dimensions of the virtual mannequin can be changed and adapted to the physical dimensions of the consumer (neck, chest, waist, hips). Consumers can, before the purchase, virtually try on a garment and choose the size that best fits their body shape. In both cases, the consumers are measured by using a measuring tape and on the basis of the obtained physical dimensions choose an appropriate size which fits them best. However, it has been shown that self-assessments are inaccurate by as much as $6 \mathrm{~cm}$ (Yoon and Radwon as cited in Ashdown \& Dunne, 2006). Authors Kim and Choi (2002) indicate that previous studies have shown that apparel consumers do not generally familiarize themselves with their body measurements (as cited in Park et al., 2009). We conclude that the apparel consumers' lack of knowledge about their body measurements, as well as the technical difficulties involved while taking those measurements, are impediments to the proper selection of clothing sizes when shopping online.

In addition, some online stores have virtual fitting rooms that utilize a 3D scanner to capture the physical body dimensions of the consumer. Based on the obtained physical dimensions, it enables the consumers to try on apparel in a virtual fitting room before they make a purchase. Studies have shown that the 3D scanner enables a reliable acquisition of the physical dimensions (Loker et al., 2004). However, for the consumers who do not belong to the target market of apparel manufacturers, the use of a 3D body scanner (i.e. the exact body measurements acquisition) does not guarantee that they will find the ready-to-wear apparel that fits their body shape. According to Ashdown and Dunne (2006), the consumer dissatisfaction with the fit of apparel is very high (62\% for men and 50\% for women). Another study shows that $70 \%$ of women aged 55 and over are dissatisfied with the fit of ready-to-wear apparel (Goldsberry et al. as cited in Ashdown \& Dunne, 2006). One of the reasons is that most manufacturers of ready-towear apparel set standard sizes depending on their target market (Anderson et al., 2001; Ashdown \& Dunne, 2006; Faust et al., 2006; Kim \& LaBat, 2013). Another reason is that "garment order initiators do not adhere to the standard sizes charts and garment manufacturers are incapable or unwilling to produce garments that meet the order initiators`specifications" (Faust et al., 2006; Xu \& Huang, 2003). A survey (Faust et al., 2006) showed a number of factors that contribute to this situation: obsolescence of the existing standards, variations in body shapes and sizes that the existing standards do not account for and marketing ploys aimed at flattering certain consumers. Moreover, the estimate of dimensions used in current 2D patterns represents only a general dimension with a small range of fundamental measurements such as neck base girth, armhole girth, bust girth, waist girth, hip girth, body depth, etc. (Fang \& Tien, 2013). Such systems do not take into account the detailed dimensions and specific surface configurations of individuals (Fang \& Tien, 2013; Ashdown $\&$ Dunne, 2006; Faust et al., 2006). Measurements of consumers even in the same size category vary (Apeagyei \& Otieno, 2007). Due to the above mentioned, consumers are forced to try on several different brands and sizes before finding the apparel that fits them best (Anderson et al., 2001), but also to try on a large number of apparel items, which does not guarantee that the consumer will find a garment that fits well (Ashdown \& Dunne, 2006). Based on the results of these studies, we can conclude that many consumers do not fall within the target group of the apparel industry and for this reason cannot find the apparel that fits their body dimensions and the desired style. It follows that the technology for the virtual fitting of ready-to-wear apparel (which uses parametric body or a 3D body scanner) is intended primarily for the consumers who, in terms of size, (dimensions of the body) belong to the target group of the apparel industry.

Different body shapes pose a challenge for the garment industry. However, the development of technology makes the fitting of the apparel to the consumers' needs possible (Lee, Kunz, Fiore, \& Campbell, 2002). With advanced 3D technology, there would certainly be substantial progress regarding fit, visualization, and manufacturing of custom-made apparel when purchasing in online stores. Ashdown and Dunne (2006) emphasized that the success patterns of a custom fit ultimately depend on the reliability of the body measurement process. Therefore, 3D body scanning systems and CAD/CAM software which includes 3D virtual apparel simulation software may carry commercial potential in the apparel industry of custom-made apparel for retail over the Internet.

To summarize, online stores can offer an alternative solution; custom-made apparel, that enables the development of apparel which fits the consumer perfectly. Also, in this way, the consumers who, according to their body dimensions, do not belong to the standard sizing system, would have the opportunity to buy apparel that corresponds to their requirements regarding fit, comfort and style.

The global apparel industry continues a positive growth trend. By 2019, the global apparel market will have grown to 1.51 trillion U.S. dollars (Statista, 2017a). A robust growth is expected in emerging markets and the United States' apparel market (Statista, 2017b). According to Eurostat (Eurostat, 2017a), in 2015, 184,205 enterprises in the EU-28 were engaged in textile and apparel manufacturing and their annual turnover was 148,610.3 million EUR. In 2014, they employed $1,431,420$ employees. On the other hand, the EU-28 countries have more than 511,000,000 (Eurostat, 2017b) potential consumers (estimated by number of persons with residence in one of these countries), while the number of potential online consumers is even higher, since the world population already exceeds 7.5 billion people. Lectra, one of the world leaders in integrat- 
ed technology solutions, expects that four critical trends will shape the global apparel industry in the next five to ten years: millennials, technology, industry 4.0 and China (McGregor, 2016). Millennials, the people born between 1981 and 1997, bring a lot of challenges for the apparel industry, since they want quality and more sustainable products at low prices. The Executive Vice President of Sales at Lectra, Edouard Macquin, forecasts that in the apparel industry, the following new technologies will become common (McGregor, 2016):"collaborative solutions, 3D rendering, connected devices and the Internet of Things, augmented reality, virtual reality and analytics, making the data speak and providing information." In Industry 4.0, an era of automatization and data exchange in the cloud, one of the major challenges will be moving from mass production to mass customization. The manufacturers and the consumers will have a direct connection, without (or at least with fewer) intermediaries (McGregor, 2016).

Based on the literature review on problems in shopping for apparel online (e.g. Loker, Ashdown, and Carnrite (2008); Kim and LaBat (2013); Yang and Young (2009); Boonbrahma, Kaewrata, and Boonbrahma (2015)) one of our objectives was to investigate the shopping experience of the consumers who purchase in the online apparel market and to investigate the individual aspects influencing the decision of consumers, who, in spite of browsing and searching do not purchase the apparel. We propose the following research questions:

- RQ1: Which factors influence online apparel purchases?

- RQ2: How many dimensions (or factors) are contained in the individual aspects influencing non-purchasing in an online environment and what is their content?

Based on the literature review on drawbacks and consumers' dissatisfaction with ready-to-wear apparel due to the use of standardized sizes and inappropriate fit, the aim of the paper is to investigate the consumers' willingness to purchase custom-made apparel tailored according to the specifications of an individual consumer, using advanced technologies. In the third research, the question (RQ3) we investigated was whether the respondents would be willing to give their body measurements while purchasing custom-made apparel online, since the accurate body measurements are a prerequisite for the production of customized apparel.

- RQ3: What proportion of the potential consumers would be willing to give their body measurements when purchasing custom-made apparel online?

\section{Methodology}

\section{Instrumentation}

We prepared a questionnaire based on several sources: Loker et al. (2004), Hosun (2012), and Yu et al. (2012). The questionnaire was tested by 10 respondents, minor grammatical errors were found and eliminated. The English version of the questionnaire was proofread by a native speaker. In the final version of the questionnaire, we decided not to set up hard warnings on all questions, instead, we decided on soft warnings that enable the respondent to complete the survey, even if they do not provide answers to all the questions. We received a proposal to replace the term "apparel", due to its archaic connotation, with a more modern term "clothing". However, on the basis of the literature review, we decided to keep the term "apparel". The questionnaire was prepared in accordance with the aims of the research and was divided into four thematic parts. The first part 'Shopping experiences' was designed to discover the importance of online apparel shopping to the consumers. All variables were measured on a 5-point Likert type scale of agreement, where 1 means 'strongly disagree' and 5 'strongly agree'.

In the second part, entitled 'Influences on the purchase', respondents were asked to estimate the factors that affected their decision to purchase the apparel online, using the 5-point scale of influence. They were also asked to estimate the factors that influence their decision not to purchase the apparel in spite of browsing and searching in online stores. In addition, we were also interested to know whether the respondents ever returned the apparel they purchased and for what reason.

The last thematic part was devoted to the development of a virtual product and to the process of online apparel shopping using advanced technology. Within this part, the respondents were asked if the following solutions would affect their online purchase of the apparel: virtual fitting of the apparel, custom-manufactured apparel according to the body dimensions using advanced technologies (3D body scanning, CAD/CAM programs, etc.), the aesthetic properties of the apparel shown as realistically as possible, a flexible date of delivery, higher quality of the apparel (materials and/or workmanship), the apparel being safe and harmless to their health and the easy purchase of the apparel.

At the end of the survey, socio-demographic questions were included, about gender, age, education, occupational status and place of residence.

\section{Data Collection}

An anonymous online survey using web portal (www.1 ka. si) was conducted in July and August 2013. The survey focused on the population that buys apparel online. 
The link to the questionnaire was published: (a) on three different forums of shopping centers worldwide, (b) on five well-known fashion forums, (c) on official Facebook forums of nine online stores of large world-renowned brands. These brands include apparel for men, women and youth and have online stores. Additionally, we asked twelve online stores of world-famous apparel brands and the students of the clothing and textile department at a U.S. university in the West to publish our questionnaire link on their Facebook pages. The decision to distribute the questionnaire via various channels was made based on the previous research where surveys were conducted mainly on students or respondents who receive special benefits to participate in the research.

Altogether we received 76 completed questionnaires. We would like to emphasize that in contrast to the majority of other studies on apparel customization, we did not offer any material incentives to the participants included in the research.

\section{Results}

\section{Sample Characteristics}

Our study included $41 \%$ men and $59 \%$ women. Their age ranged between 22 and 48 (with the average age of 33). More than half of the respondents (59\%) have a university diploma and $76 \%$ are employed. The majority of the respondents (80\%) are from Europe (Slovenia 57\%; Serbia $24 \%$; and the rest of the respondents were from Montenegro, Austria, Bosnia and Herzegovina, Bulgaria, France, Italy, Russia and the United Kingdom). The other respondents were from the USA and Australia (Table 1).

\section{Descriptive Statistics for Online Shopping Experiences}

In the first thematic part, the respondents answered several questions on online shopping apparel experiences and views using the 5-point Likert type scale of agreement.

It turned out (Table 2) that the respondents mostly believe that online shopping for apparel is 'Time saving' for them $(M=3.84)$. The other three options received lower means, 'Fun' $(M=3.25)$, 'Pleasure' $(M=3.10)$ and 'Obligation' $(M=2.30)$.

Table 1: Sample characteristics

\begin{tabular}{|c|c|c|c|}
\hline & & Group & $\%$ \\
\hline \multirow{2}{*}{ Gender } & & Men & $41 \%$ \\
\hline & & Women & $59 \%$ \\
\hline \multirow{3}{*}{ Age } & & $20-30$ years & $29 \%$ \\
\hline & & $31-40$ years & $61 \%$ \\
\hline & & $41-50$ years & $10 \%$ \\
\hline \multirow{4}{*}{ Education } & & Less than High school diploma & $5 \%$ \\
\hline & & A levels/High school diploma & $15 \%$ \\
\hline & & Bachelors degree/University & $46 \%$ \\
\hline & & Master's Research degree, PhD Degree & $20 \%$ \\
\hline \multirow{12}{*}{ Country } & \multirow{10}{*}{ Europe } & Austria & $2 \%$ \\
\hline & & Bosnia and Herzegovina & $2 \%$ \\
\hline & & Bulgaria & $2 \%$ \\
\hline & & France & $2 \%$ \\
\hline & & Italy & $2 \%$ \\
\hline & & Montenegro & $4 \%$ \\
\hline & & Russia & $2 \%$ \\
\hline & & Serbia & $24 \%$ \\
\hline & & Slovenia & $57 \%$ \\
\hline & & The United Kingdom & $2 \%$ \\
\hline & America & North America & $18 \%$ \\
\hline & Australia and Oceania & Australia and Oceania & $2 \%$ \\
\hline
\end{tabular}


Table 2: Viewpoints on online apparel shopping

\begin{tabular}{|c|c|c|c|}
\hline Online apparel shopping represents... & $\boldsymbol{N}$ & $\boldsymbol{M}$ & $\boldsymbol{S D}$ \\
\hline ... pleasure & 63 & 3.10 & 1.21 \\
\hline ... fun & 63 & 3.25 & 1.05 \\
\hline . . obligation & 57 & 2.30 & 1.05 \\
\hline .. time saving & 62 & 3.84 & .96 \\
\hline \multicolumn{2}{|l}{}
\end{tabular}

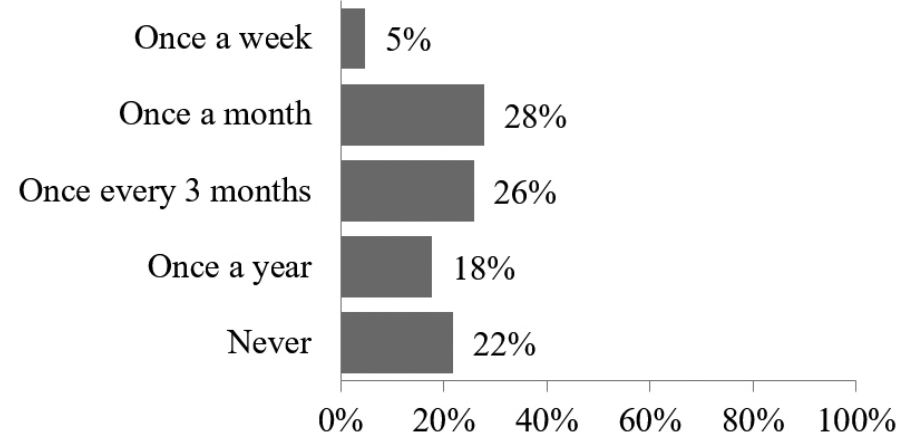

Figure 1: Frequency of purchasing apparel online

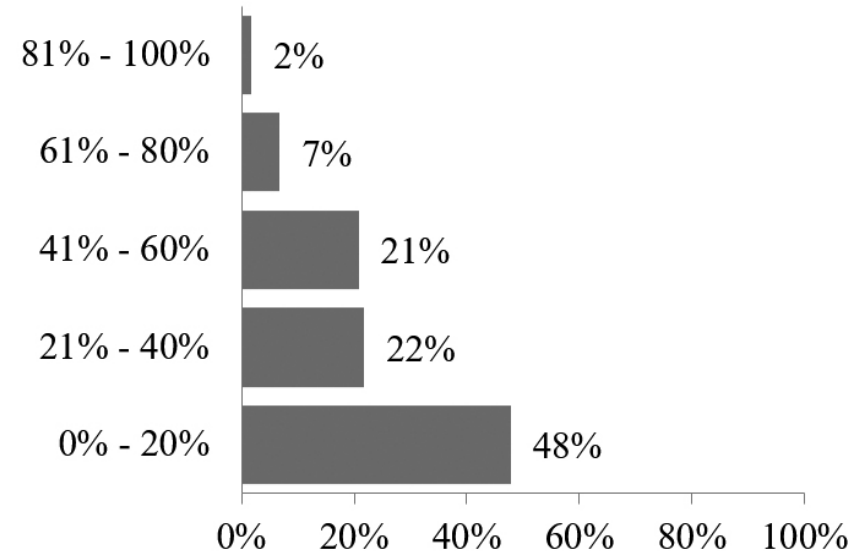

Figure 2: Percentage of online purchases in the last 12 months

Further, we wanted to know how often they purchase apparel online. The majority of respondents make online purchases once a month (28\%) or once every three months $(26 \%)$. They are followed by consumers who have never bought apparel online $(22 \%)$ and those who buy once a year $(18 \%)$, while the rest of the respondents purchase online once a week (Figure1).

Since the consumers are purchasing both in traditional and online shops we wanted to know what percentage of all the apparel bought in the last year they bought online. It turned out that the traditional shopping still prevails over online shopping. Namely, the majority of respondents
(48\%) bought at most $20 \%$ of apparel online, followed by consumers who bought $21 \%-40 \%$ of apparel online (22\%) and consumers who bought $41 \%-60 \%$ (21\%). Only $2 \%$ of the respondents bought online more than $80 \%$ of the apparel in the last year (Figure2).

In the second thematic part of the questionnaire and in RQ1, we were interested to know how much the given elements affect online apparel purchasing. The respondents answered using the 5-point scale of influence, and the results are presented in Table 3. On average, they decide on online shopping mostly because of 'Time saving' $(M=$ 4.19), 'Avoiding crowds' $(M=3.92)$ and 'Home delivery' 
Table 3: Factors affecting online apparel purchases

\begin{tabular}{|c|c|c|c|}
\hline Variables & $\boldsymbol{N}$ & $\boldsymbol{M}$ & $\boldsymbol{S D}$ \\
\hline Online shopping is fun. & 49 & 3.20 & .98 \\
\hline Time saving & 48 & 4.19 & .76 \\
\hline Avoiding crowds & 48 & 3.92 & 1.01 \\
\hline Home delivery & 48 & 3.88 & .84 \\
\hline
\end{tabular}

Table 4: The descriptive statistics of nine variables measuring individual aspects that influence the consumers' decision not to purchase apparel in spite of browsing and searching.

Note. $N$ - number of observations, $M-$ mean, $S D$ - standard deviation

\begin{tabular}{|l|c|c|c|}
\hline Variables & $\boldsymbol{N}$ & $\boldsymbol{M}$ & $\boldsymbol{S D}$ \\
\hline No personal contact with apparel (i.e. touch and feel, weight). & 43 & 3.56 & .959 \\
\hline Cannot try on apparel (i.e. fit, comfort, appearance). & 43 & 3.84 & 1.153 \\
\hline Visual and aesthetic risk (i.e. style, color and print, matching with other apparel). & 43 & 3.51 & 1.009 \\
\hline Aesthetic properties (style, color and print) are not realistically shown. & 43 & 3.60 & .979 \\
\hline I am not sure about fit and size. & 43 & 3.93 & .961 \\
\hline The risk of getting used apparel in spite of ordering it brand new. & 43 & 2.56 & 1.053 \\
\hline Delivery date is not flexible. & 43 & 2.74 & .928 \\
\hline Cannot assess the quality of apparel (fiber, manufacturing). & 43 & 3.23 & .947 \\
\hline Browsing and searching for apparel is very time-consuming. & 43 & 2.88 & 1.005 \\
\hline
\end{tabular}

$(M=3.88)$. As the least important element, they estimated that 'Online shopping is fun' $(M=3.20)$.

One of the problems that online shops are facing is returning the product. More than half (59\%) of the respondents who are purchasing online said that they already returned an apparel item they had purchased online. As the most common cause they estimate 'the size does not match' $(45 \%)$, while only $2 \%$ of respondents stated that the reason was 'Damaged on delivery'.

\section{Descriptive Statistics for Variables Indicating Reasons for Non-purchasing in Online Stores}

In addition, we asked the respondents about the individual aspects that have influenced their decision not to purchase the apparel, in spite of browsing and searching in an online store. The respondents provided their answers on the 5 -point scale of influence ( 1 meaning 'no influence' and 5 meaning 'big influence'). According to Table 4, the aspect with the highest influence on the decision not to purchase the apparel in spite of browsing and searching for it, is 'unsure about fit and size' $(M=3.93)$. The aspect with the second highest impact is 'cannot try on the apparel' $(M$ $=3.84$ ), followed by the aspect 'the aesthetic properties (style, color and print) are not realistically shown' $(M=$ 3.60). The aspect with the lowest impact on the decision not to purchase is 'the risk of getting used apparel in spite of ordering it brand new' $(M=2.56)$.

Factor Analysis for Individual Aspects Influencing Non-Purchasing Apparel Online

As stated above, in spite of browsing and searching, some consumers do not end up making a purchase. In order to analyze individual aspects influencing non-purchasing in an online environment, an exploratory factor analysis was performed. The analysis was based on nine variables measuring individual aspects influencing the decision of consumers not to make an online purchase of the apparel in spite of browsing and searching. The descriptive statistics are presented in Table 4.

One could argue that the sample is too small to perform a factor analysis as we do not have at least 100 cases and case-to-variable ratio is far below 10 , but based on the empirical data, Arrindell and van der Ende (as cited in Field, 2013) concluded that the case-to-variable ratio made little difference to the factors' solutions. More important than the overall sample, the size and ratio between cases and variables in the stability of the obtained solution are factor loadings. If at least four factor loadings are above .6, then the factors are reliable regardless of the sample size (Guadagnoli \& Velicer, 1988), and Table 6 shows that we got two factors where the first one has all the factor loadings above .76 and the other has all the factor scores above .71, 
Table 5: Eigenvalues and the percentage of explained variance

Note. Extraction Method: Principal Component Analysis

\begin{tabular}{|c|c|c|c|c|c|c|}
\hline \multirow{2}{*}{ Component } & \multicolumn{3}{|c|}{ Initial Eigenvalues } & \multicolumn{3}{|c|}{ Loadings } \\
\hline & Total & $\%$ of Variance & Cumulative \% & Total & $\%$ of Variance & Cumulative \% \\
\hline 1 & 3.754 & 41.708 & 41.708 & 3.754 & 41.708 & 41.708 \\
\hline 2 & 2.202 & 24.469 & 66.177 & 2.202 & 24.469 & 66.177 \\
\hline 3 & .718 & 7.975 & 74.152 & & & \\
\hline 4 & .617 & 6.852 & 81.004 & & & \\
\hline 5 & .526 & 5.847 & 86.851 & & & \\
\hline 6 & .426 & 4.733 & 91.584 & & & \\
\hline 7 & .299 & 3.318 & 94.902 & & & \\
\hline 8 & .249 & 2.764 & 97.667 & & & \\
\hline 9 & .210 & 2.333 & 100.000 & & & \\
\hline
\end{tabular}

Table 6: Rotated 'pattern' component matrix

Note. Extraction Method: Principal Component Analysis. Rotation Method: Oblimin with Kaiser Normalization.

The factor scores smaller than 3 are suppressed, variables are ordered according to the decreasing factor scores.

\begin{tabular}{|l|c|c|}
\hline \multirow{2}{*}{ Variables } & Component & $\mathbf{1}$ \\
\cline { 2 - 3 } & $\mathbf{2}$ & $\mathbf{. 8 8 7}$ \\
\hline Cannot try on apparel (i.e. fit, comfort, appearance). & $\mathbf{. 8 0 9}$ & $\mathbf{. 8 0 5}$ \\
\hline Visual and aesthetic risk (i.e. style, color and print, matching with other apparel). & $\mathbf{. 7 7 5}$ \\
\hline No personal contact with apparel (i.e. touch and feel, weight). & $\mathbf{. 7 6 3}$ \\
\hline Aesthetic properties (style, color and print) are not realistically shown. & & $\mathbf{. 8 3 0}$ \\
\hline I am not sure about fit and size. & $\mathbf{. 7 4 0}$ \\
\hline Delivery date is not flexible. & $\mathbf{. 7 1 1}$ \\
\hline The risk of getting used apparel in spite of ordering it brand new. & $\mathbf{. 7 0 7}$ \\
\hline Browsing and searching for apparel is very time-consuming. & & .366 \\
\hline Cannot assess the quality of apparel (fiber, manufacturing). & & \\
\hline
\end{tabular}

indicating that our solution is reliable.

Further, the reliability of the questionnaire was tested with the Cronbach's Alpha Coefficient, where it turned out that the questionnaire has quite a high reliability, $\alpha=.802$. In addition, the adequacy of the sample was confirmed with Kaiser-Meyer-Olkin test, $\mathrm{KMO}=.805$ (it is 'good' according to Hutcheson and Sofroniou (1999) and Field (2013)). Bartlett's test of sphericity $(36)=166.35, \mathrm{p}<.000$, indicating that correlations between items are sufficiently large for performing the Principal Component Analysis. The multi-collinearity was ruled out based on the inspection of the correlation matrix, where the largest significant correlation coefficient between 'aesthetic properties (style, color and print) are not realistically shown' and 'visual and aesthetic risk (i.e. style, color and print, matching with other apparel)' was equal to .692 ( $\mathrm{p}<.000)$, which is far below .8. In addition, the value of the determinant of the correlation matrix should be greater than .00001 (Field,
2013), and in our case it was equal to .013.

Among nine individual aspects that influence the consumers' decision not to purchase the apparel online, in spite of browsing and searching, two factors were revealed based on three common rules of extraction (Field, 2013): (i) Kaiser's criterion of extracting factors with eigenvalues higher than $1\left(\lambda_{1}=3.7, \lambda_{2}=2.20, \lambda_{3}=.72\right)$, (ii) the 'scree' plot (not reported here but can be reconstructed with eigenvalues from Table 5), which clearly shows the point of inflexion at the third factor suggesting that the solution contains two factors, and (iii) the total percentage of explained variance was greater than $60 \%$ since it was equal to $66 \%$ (Table 5). Therefore, an answer to the first part of RQ2 is that there are two dimensions (or factors) based on individual aspects influencing non-purchasing in an online environment.

Table 6 shows factor loadings after the oblimin rotation. It should be noted that the factor scores lower than 
.3 are suppressed and that variables are ordered according to the decreasing factor scores. The content of both dimensions obtained from individual aspects influencing non-purchasing in an online environment (the second part of RQ2) can be obtained from the factor scores in Table 6 . For each variable, the factor score written in bold indicates to which factor it belongs. The items that cluster on the first factor suggest that it represents a 'misperception of product integrity', while the second factor represents 'browsing and delivery issues with overall quality'. Several authors (e.g. Field (2013)) suggest that the reliability should be calculated for subscales rather than theoretical scales or the whole questionnaire. Therefore, we calculated Cronbach's Alpha coefficients for both obtained factors. Cronbach's Alpha Coefficient for the first factor is equal to 0.872 , and for the second factor it is equal to 0.753 , indicating that both subscales are highly reliable.

The factor scores smaller than .3 are suppressed, variables are ordered according to the decreasing factor scores. The correlation coefficient between both obtained factors is equal to .126 , indicating that they are weakly connected, so we tried the orthogonal varimax rotation, as well. The solution was practically the same, with slightly different factor loadings. Therefore, we decided to keep and interpret the non-orthogonal solution presented above.

\section{Analysis of Consumer Attitudes Toward Improved Shopping Experiences and Their Willingness to Pur- chase Custom-Made Apparel}

Having in mind the limitations of today's standard sizing system of ready-to-wear apparel and the technological advances in the textile industry, we proposed some solutions that can improve shopping experiences and the whole concept of online apparel shopping. Therefore, in the last thematic part we were interested to know which of the proposed improved shopping experiences would affect the respondent's decision about their online apparel purchases. It turned out that the vast majority of respondents think that all the proposed solutions would positively affect their decision to purchase. More precisely, 'easy purchase of the apparel' was selected by $93 \%$ of the respondents, 'aesthetic properties of apparel are shown as realistically as possible' by $85 \%$, 'higher quality of apparel' by $82 \%$, 'apparel that is safe and does not present a health risk' by $80 \%$, 'an option to virtually try on the apparel' by $73 \%$, 'an option to custom manufacture the apparel to your measurements with the use of advanced technologies, e.g. body scanning or CAD/CAM' by $72 \%$, and 'flexible date of delivery' by $57 \%$. In this part, we were also interested to know whether the respondents would be willing to give their body measurements when purchasing custom-made apparel online. According to RQ3, it turns out that a high proportion of the respondents $(93 \%)$ is willing to share their body dimensions.

\section{Discussion}

Our study showed that online shopping for apparel is most attractive due to saving time and its amusement aspect, providing a high level of pleasure. Two of the most important reasons for not purchasing, despite browsing and searching in online stores are that potential consumers are not sure about the right size and they cannot try on the apparel. Similar results were established in several other studies (e.g. Yang \& Young (2009), Yu et al. (2012)), as well.

Our investigation of the individual aspects influencing non-purchasing in an online environment revealed two factors based on nine measured aspects that influence the decision of consumers not to purchase the apparel online despite browsing and searching. The first factor, 'misperception of product integrity', refers to the aesthetic and functional characteristics of the apparel which should be superb and satisfy the consumer's expectations in every aspect, including comfort, fit, color and pattern. Online consumers of ready-to-wear apparel may be discouraged from purchase, especially due to the dissatisfaction with the fit of ready-to-wear apparel, as a result of the lack of direct experience with the product on the Internet. However, despite the efforts of online retailers to provide a better virtual experience with the help of interactive technology (e.g. expansion or zoom, 3D rotation, personal 3D models in a virtual fitting room), and easier selection of the appropriate size using the information about standard sizes and measurement procedure provided on their websites, consumers in online stores are still not completely sure which size fits them best and whether apparel is comfortable to wear. Fulfilling the consumer's preferences regarding apparel fit, meaning to enable an adequate relationship between the body, garment dimensions and the consumer's expectations about how they want it to fit, is possible to achieve with a custom-made apparel service via the Internet. Our results indicate that the solutions which use advanced technologies for purchasing custom-made apparel online, would positively influence the consumer's decision to purchase on the online apparel market. Furthermore, the results of our study show that a high proportion of the respondents (93\%) is willing to share their body dimensions in order to improve the fit of custom-made apparel.

The second factor reveals 'browsing and delivery issues with overall quality' and includes more heterogeneous aspects of online shopping. Variables 'Cannot assess the quality of apparel (fiber, manufacturing)' and 'The risk of getting used apparel in spite of ordering it brand new' refers to the overall quality of the purchased apparel, while the other two variables relate to the time issues of time-consuming Internet browsing and unknown and/ or inaccurately estimated delivery time. The second factor shows a quite unique dimension of browsing, delivery issues and concerns about receiving used apparel which was not stressed in previous studies. 


\section{Conclusions}

Technology development makes it possible for apparel to meet the consumer's expectations (Lee et al., 2002). With advanced 3D technology (3D body scanning and automated CAD software for custom pattern generation, 3D simulation and visualization of apparel with realistic materials properties) there would certainly be significant progress regarding the fit, visualization, and manufacturing of custom-made apparel when purchasing in online stores.

The results of our study show that the proposed solutions to improve the online apparel purchasing, such as making custom apparel using advanced technologies (scanner body, CAD/CAM software, etc.), the possibility of virtually trying on the apparel, realistic aesthetic properties of apparel, high quality (materials and/or manufacturing) of apparel, safe apparel and an easy process for purchasing apparel, have a positive impact on the decision of the consumers to purchase on the global online apparel market. Also, the results of our study demonstrated that the consumers are willing to give their body measurements for the manufacturing of custom-made apparel.

Therefore, in the future, it is necessary to focus on the development of a system which will allow an easy online purchase of custom-made apparel of high quality at a lower cost. In order to move in this direction, it is necessary to further develop the technology and integrate it into the system. In addition, a cost efficiency analysis of such a system should be conducted from both the consumers' and the manufacturers' perspectives. After the implementation of such a system, the consumers' satisfaction with custom-made apparel bought online should be investigated based on several factors (e.g. personal characteristics, fashion involvement, body satisfaction, purchase behavior, general attitude towards novelties with an emphasis on new technologies) that can potentially impact the intention to use it. In cooperation with online shops providing virtual fitting rooms, a research investigating reasons (e.g. dissatisfaction with the fit) for returning apparel needs to be conducted.

The main limitation of the research is a low response rate, but we have to emphasize that we did not offer any financial or other benefits to the respondents participating in the study, in contrast to the majority of other studies on apparel customization. Another drawback of the study is that we did not ask the respondents about their body measurements, usual standardized sizing, and their satisfaction with their looks. In cooperation with online stores, reasons for returned apparel due to inappropriate fit could be investigated in more detail, as well as the consumers' willingness to purchase custom-made apparel and their satisfaction with the purchase of custom-made apparel, as well as the overall shopping experience.

Future research should investigate differences related to individual aspects influencing non-purchasing in an online environment and the consumers' willingness to purchase custom-made apparel among respondents from different continents (or countries). In addition, further research should focus on millennials, and their attitudes toward custom-made apparel and positive online shopping experiences, since they account for more than " $40 \%$ of retail spending worldwide and that share is only going to grow", as pointed out by McGregor (2016).

\section{Literature}

Anderson, L.J., Brannon, E.L., Ulrich, P.V., Presley, A.B., Woronka, D., Grasso, M., \& Gray, S. (2001). Understanding fitting preferences of female consumers: Development an expert system to enhance accurate sizing selection. National Textile Center. National Textile Center Annual Report. Retrieved from http://infohouse.p2ric.org/ref/08/07197.pdf

Apeagyei, P. R., \& Otieno, R. (2007). Usability of pattern customising technology in the achievement and testing of fit for mass customisation. Journal of Fashion Marketing and Management, 11 (3), 349-365, http:// doi.org/10.1108/13612020710763100

Ashdown, S. P., \& Dunne, L. (2006). A Study of Automated Custom Fit: Readiness of the Technology for the Apparel Industry. Clothing and Textiles Research Journal, 24 (2), 121-136, http://doi. org/10.1177/0887302X0602400206

Boonbrahm, P., Kaewrat, C., \& Boonbrahm, S. (2015). Realistic Simulation in Virtual Fitting Room Using Physical Properties of Fabrics. International Conference on Virtual and Augmented Reality in Education. Procedia Computer Science, 75 (2015), 12-16, https:// doi.org/10.1016/j.procs.2015.12.189

Chattaraman, V., Simmons, K. P., Ulrich, P.V. (2013). Age, Body Size, Body Image, and Fit Preferences of Male Consumers. Clothing and Textiles Research Journal, 31 (4), 291-305, https://doi. org $/ 10.1177 / 0887302 \times 13506111$

Eurostat (2017a). Annual detailed enterprise statistics for industry (NACE Rev. 2, B-E). Retrieved August 2, 2017 from http://appsso.eurostat.ec.europa.eu/nui/submitViewTableAction.do

Eurostat (2017b). Population on 1 January. Retrieved August 2, 2017, from http://ec.europa.eu/eurostat/ tgm/table.do?tab=table\&init=1\&language $=$ en $\& p-$ code $=$ tps $00001 \&$ plugin $=1$

Fang, J. J., \& Tien, C.-H. (2013). Trimmed NURBS surface applications in computerized 3D fashion design for garment industry. International Journal of Clothing Science and Technology, 25 (1), 24-42, http://doi. org/10.1108/09556221311292192

Faust, M. E., Carrier, S., \& Baptiste, P. (2006). Variations in Canadian women's ready-to-wear standard sizes, Journal of Fashion Marketing and Management. 10 
(1), 71-83, http://doi.org/10.1108/13612020610651132

Field, A. (2013). Discovering statistics using IBM SPSS Statistics. (4rd ed.). London, United Kingdom: Sage Publication Ltd.

Guadagnoli, E., \& Velicer, W. F. (1988). Relation of sample size to the stability of component patterns. Psychological Bulletin. 103 (2), 265-275, http://doi. org/10.1037/0033-2909.103.2.265

Gültepe, U., \& Güdükbay, U. (2014). Real-time virtual fitting with body measurement and motion smoothing. Computers \& Graphics. 43, 31-43. https://doi. org/10.1016/j.cag.2014.06.001

Hosun, L. (2012). Analysis of Utilization of Virtual Try on Simulation and Consumers' Preference in Apparel Online Shopping. Journal of the Korean Society for Clothing Industry, 14 (1), 83-89, http://dx.doi. org/10.5805/KSCI.2012.14.1.083

Hutcheson, G., \& Sofroniou, N. (1999). The multivariate social scientist. London, United Kingdom: Sage.

Kim, K., Innami, N., Takatera, M., Narita, T., Kanazawa, M., \& Kitazawa, Y. (2017). Individualized male dress shirt adjustments using a novel method for measuring shoulder shape. International Journal of Clothing Science and Technology, 29(2), 215-225, https://doi. org/10.1108/IJCST-02-2016-0011

Kim, D. E., \& LaBat, K. (2013). Consumer experience in using $3 \mathrm{D}$ virtual garment simulation technology. The Journal of The Textile Institute. 104 (8), 819-829. http://doi.org/10.1080/00405000.2012.758353.

Kozar, T., Rudolf, A., Cupar, A., Jevšnik, S., Stjepanovic, Z. (2014). Designing an Adaptive 3D Body Model Suitable for People with Limited Body Abilities. Journal of Textile Science \& Engineering, 4 (5), 1-13, http://dx.doi.org/10.4172/2165-8064.1000165

Lee, S. E., Kunz, G. I., Fiore, A. M., \& Campbell, J. R. (2002). Acceptance of Mass Customization of Apparel: Merchandising Issues Associated With Preference for Product, Process, and Place. Clothing and Textiles Research Journal, 20 (3), 138-146, http://doi. org $/ 10.1177 / 0887302 X 0202000302$

Loker, S., Ashdown, S. P., Cowie, L., \& Schoenfelder, K. A. (2004). Consumer interest in commercial applications of body scan data. Journal of Textile and Apparel, Technology and Management, 4(1), 1-13.

Loker, S., Ashdown, S., \& Carnrite, E. (2008). Dress in the Third Dimension: Online Interactivity and Its New Horizons. Clothing and Textiles Research Journal, 26 (2), 164-176, http://doi.org/10.1177/0887302X08315176

McGregor, L. (2016). 4 Trends That Will Impact the Apparel Industry. Retrieved from https://sourcingjournalonline.com/4-trends-will-impact-apparel-industry/

Monsuwe, T. P., Dellaert, B. G., \& Ruyter, K. (2004). What drives consumers to shop online? A literature review, International Journal of Service Industry Management, 15 (1), 102-121, http://dx.doi. org/10.1108/09564230410523358
Niculescu, C., Mielicka, E., Salistean, A., Napieralska, L., Popescu, G., Mocenco, A. (2016). Web portal for customized production of clothing for overweight and elderly people. Industria Textila, 67 (3), 194-200.

Olaru, S., Filipescu, E., Niculescu, C., \& Filipescu, E. (2013). Morphological assessment of human body for clothing patterns desing. Industria Textila, 64 (5), 254259.

Orzan, G., Iconaru, C., Popescu, I. C., Orzan, M., \& Macovei, O. I. (2013). PLS-based SEM analysis of apparel online buying behavior. The importance of eWom, Industria Textila. 64 (6), 362-367.

Park, J., Nam, Y., Choi, K. M., Lee, Y., \& Lee, K. H. (2009). Apparel consumers' body type and their shopping characteristics. Journal of Fashion Marketing and Management, 13 (3), 372-393, http://doi. org/10.1108/13612020910974500

Pilar, T., Stjepanovič, Z., \& Jevšnik, S. (2013). Ocenjevanje prileganja $3 \mathrm{D}$ virtualno izdelanih prototipov kril telesu. [Evaluation of fitting virtual 3D skirt prototypes to body.]. Tekstilec, 56(1), 47-62. Retrieved from $\quad$ https://www.dlib.si/?URN=URN:NBN:SI:DOC-AORLFH3H

Statista (2017a). Global apparel market/industry size 2012-2025. Retrieved August 24, 2017, from https:// www.statista.com/statistics/279757/apparel-market-size-projections-by-region/

Statista (2017b). Retail sales of the global apparel market 2012-2021. Retrieved August 24, 2017, from https:// www.statista.com/statistics/732546/global-apparel-market-retail-sales-value/

Yang, K., \& Young, A. P. (2009). The effects of customized site features on internet apparel shopping. Journal of Fashion Marketing and Management, 13 (1), 128-139. http://doi.org/10.1108/13612020910939923

Yu, U. J., Lee, H. H., \& Damhorst, M.L. (2012). Exploring Multidimensions of Product Performance risk in the Online Apparel Shopping Context: Visual, Tactile, and Trial Risks. Clothing and Textiles Research Journal, 30 (4), 251-266. http://doi. org/10.1177/0887302X12462059 
Milica Žuraj received her bachelor's degree in 2012 and masters' degree in 2015 in orga-nizational sciences at the University of Maribor, Faculty of Organizational Science. Her main research interests are cross-cultural training of expatriates, and customer willingness to purchase apparel online using advanced technologies.

Petra Šparl († in 2016) was an Associate Professor of Mathematics at the Faculty of Organizational Sciences, University of Maribor, Slovenia. Her main research in- terests were graph theory, data analysis and students' performance in methodological courses.

Anja Žnidaršič is an Assistant Professor of Quantitative Methods at the Faculty of Organizational Sciences, University of Maribor, Slovenia. Her main research interests are social network analysis, micro-enterprises and information-communication technology, and students' performance in methodological courses. 